\title{
Advantages and Implementation Steps of BIM-based Construction Project Management
}

\author{
Xiang Li, Lei Cao \\ Yellow River Conservancy Technical Institute, Henan, 475003, China
}

\begin{abstract}
Key words: BIM technology, Construction project management, Advantage.
\end{abstract}
\begin{abstract}
BIM technology is building information modeling based on construction project, relevant information and data. Digital information technology can be used to simulate all kinds of information of construction project, so it is widely applied in construction project management. This paper mainly discusses and analyzes advantages and implementation steps of BIM-based construction project management.
\end{abstract}

\section{Introduction}

BIM technology is building information modeling which combines 3D digital technology, information technology and relevant information. It expresses relevant information of construction project in digital form and offers effective help for construction project management ${ }^{[1]}$. Construction industry in China develops rapidly. Improvement of construction project management quality is the key to guaranteeing construction project quality. Thus, it is necessary to rationally apply BIM technology to manage construction project and give full play to advanategs of BIM technology.

\section{Brief introduction to BIM technology}

BIM refers to Building Information Modeling. BIM technology is a new digital technology which was created by Prof. Chuck Eastam (Georgia Institute of Technology) in $1975^{[2]}$. The creation of BIM technology makes quantification and visualization of construction project achieved and gradually optimizes operation mode of construction project management. Hence, it exerts important influence on development of construction industry. On the one hand, BIM technology changes traditional 2D spatial analysis mode of engineering construction and brings authentic 3D space. On the other hand, BIM technology can utilize digital technology to establish engineering information base according to actual conditions of engineering, mainly including status information and specialty information of constructional engineering as well as building construction information etc ${ }^{[3]}$. Meanwhile, non-component objects such as movement behavior and space state information can be shown through 3D model so as to promote integrated development of constructional engineering and achieve visual control of construction project from design to completion. In this way, project quality can be ensured, and cost input can be reduced effectively.

\section{Advantages of BIM-based construction project management}

BIM-based construction project management has many advantages such as enhancing productivity, shortening construction period, improving project quality and reducing cost. Its advantages are mainly reflected in the following aspects. (1) Strong visual impact and high bid winning rate. In bidding management of construction project, BIM technology is used to propagandize, which has authentic and direct visual impact effect. (2) Improve plan accuracy and reduce unnecessary waste. 
Since construction project owns mass data information, project management difficult is large. Data omission and distortion may occur easily. In this case, investment decision-making lacks accurate data support, and the plan lacks rationality and accuracy. Meanwhile, unnecessary waste will increase, which leads to the cost rise. (3) Fast calculation speed and high precision. The establishment of 5D association database with BIM technology can greatly promote data calculation speed In addition, BIM database has component-level data granularity, so calculation precision can improve effectively and thus management efficiency can improve. (4) Multi-calculation and comparison, and enhancement of risk control. Data are the precondition of management. Construction project management is also based on engineering data. Thus, improvement of timeliness, effectiveness, authenticity and accuracy of engineering data acquisition is one of key factors enhancing core competitiveness of an enterprise. BIM database can fast and accurately acquire all kinds of basic information of constructional engineering at any time. On this basis, multi-calculation and comparison with plan, contract, practical unit price, consumption and total price are conducted to accurately analyze profit and loss of project operation, subpackage unit price control and consumption and enhance construction project risk control. (5) Virtual construction can help discover problems and reduce rework. BIM has 3D visualization function. Virtual construction can be conducted in combination of time dimension. Through virtual construction, potential problems or existing problems in construction technology and practical construction process can be found in time. Supervisors, construction side and the owner etc, can be contacted in time for communication to eliminate or solve construction problems. Thus, the construction unit can apply BIM technology to carry out advance virtual construction and then further optimize construction plan. This can reduce rework caused by all kinds of conflicts in the construction process to the largest extent. Meanwhile, construction efficiency improves and construction quality is guaranteed. (6) Coordinate conflict and provide strong support for decision making. Quantification is one of major features of BIM database. Various basic data in the database can be shared and coordinated among each department, which can effectively avoid unnecessary conflicts or coordinate conflicts in time when conflicts happen. For example, engineering information can be decomposed, summarized and analyzed according to component type and time-space dimension to offer strong data support for decision-maker's project investment management and schedule management.

\section{Implementation steps of BIM-based construction project management}

\section{Application of BIM technology in architectural engineering design management}

\section{Construction site investigation}

In architectural engineering design, the quality of design scheme will be influenced by construction site environment. Thus, it is necessary to investigate and analyze construction site before engineering design, including landform, environmental condition, landscape planning and traffic flow ${ }^{[4]}$. Many defects exist in traditional construction site investigation and affect engineering design quality, such as valuing qualitative analysis, ignoring quantitative analysis, large influence of subjective factors, low data processing efficiency and slow response. BIM technology is applied for construction site investigation. The combination of BIM technology and GIS technology can carry out 3D simulation of construction site environment and buildings, gain effective data, fast process and analyze data, provide accurate, effective and all-round data for constructional engineering planning, improve engineering design quality and achieve the optimal layout of constructional engineering.

Assistance of engineering proposal design

In architectural engineering design link, traditional software carries out design in 2D space. Although it can meet basic design task, it has serious shortcomings in comprehensiveness and precision of architectural design and space design. In 2D environment, it is difficult for the designer to effectively master the space feeling, and the designer cannot design 3D graph. In such case, the graph lacks 3D and visual effect. Thus, depressed or spacious internal space of buildings often occurs after the 
project is completed. With the application of BIM technology, architectural design and space design can be accurately grasped through modeling information. Besides, rational feedback to information can be made. Thus, parameterization can be achieved in scheme design to promote design scheme diversity. Moreover, for the design of building with complex appearance, parameters can be adjusted anytime to design different schemes according to changes of architectural form through the application of BIM. After performance comparison, the optimal scheme can be chosen. This can not just alleviate the designer's workload, but also improve architectural engineering design and provide good basis for construction and project management.

\section{Building performance evaluation}

Traditional building performance evaluation method is based on traditional architectural design. The former just utilizes building model for building appearance design, simply sketches architectural form and then uses 2D software for function and space design after the design is completed. Thus, building performance analysis can only be based on relevant experience or relevant algorithms to evaluate building comfort, and it lacks real data support. Meanwhile, in terms of building achievement evaluation, building industry in China mostly applies static effect pictures to display architectural design idea, while static effect is processed and rendered by relevant software in the later stage. Although appearance of the pictures is ideal, there are still many problems. For example, static effect pictures mostly display some parts and cannot show internal effects, let alone embellish and observe the building from a part or angle. The difference with actual building is large. BIM technology can make up for the defects of traditional method. The designer can apply BIM technology to comprehensively and scientifically evaluate the entire layout, color, lighting, resource, energy consumption and safety of architecture scheme. Then, the designer can effectively evaluate whether architectural design ideal conforms to sustainable development concept according to structural analysis data, and whether the design scheme is feasible. Architectural design scheme runs through the whole process of constructional engineering construction and the whole life service. So, it is very important. Building performance and design scheme can be evaluated in an all-round and scientific manner by the application of BIM technology. Besides, safety and stability of engineering construction and application can be ensured. As well, BIM technology has visualization function, so the designer can supervise and manage architectural engineering design and performance evaluation in an all-round way, discover the defects and improve in time. Therefore, BIM technology can offer interactive, vivid and comprehensive dynamic building models for constructional engineering investment enterprises. Compared with traditional static effect pictures, dynamic building models are more convictive.

\section{Application of BIM technology in construction management}

\section{Dynamic management of construction resources}

When BIM is used for dynamic management of engineering construction resources, first of all, multiple corresponding quota resource templates or pricing list should be designed according to actual engineering conditions. Then, uniform calculation and analysis should be done for 3D construction section, WBS node, construction human resource, construction quantity, machinery consumption and material consumption. Next, actual consumption is compared with estimated consumption. Finally, it is required to formulate corresponding construction resource management plan according to the contrastive analysis result, optimize construction resource allocation and reduce resource waste.

\section{Construction schedule management}

At present, building industry in China develops well, and engineering construction presents large-scale, diversified and complex development. Multiple types of work are involved in engineering construction. Besides, organization structure, technology and management score of each construction procedure differ to varying degrees. Construction information fails to be completely shared, and is relatively independent. Thus, such problems as irrational connection among each construction procedure and improper cooperation may occur easily. These problems will delay 
construction schedule and finally lead to the cost rise. The application of BIM technology in construction project schedule management is also called 4D application of BIM technology. BIM is applied to establish software group. The software group has high interface technology. Besides, the communication among each kind of software in the group is very smooth. The application of BIM technology in construction schedule management is mainly based on project management software such as P3 and Microsoft Oroject. Then, it is connected with Revit series of software to analyze construction schedule information through 3D building information modeling. Construction risk evaluation system can be established on BIM data platform. IFC analyzer is used to gain construction data files from BIM system and analyze construction schedule in combination of case-based reasoning. Finally, complete risk countermeasures are formulated according to actual conditions to achieve dynamic management of construction schedule.

Construction quality and safety management

Construction quality and safety management are key contents of construction project management. When BIM technology is applied in construction project management, the supervising unit and construction unit can data about construction safety and quality inspection in BIM database in time according to construction quarter. BIM system will connect manual inspection report, safety report, quality report and other relevant information with 4D information model. Then, safety quality and WBS node of component construction and construction section can be inquired through system inquiry function. In this way, current detailed conditions of construction can be known. On this basis, BIM system will automatically generate construction safety and quality analysis report and offer scientific basis for construction safety and quality management.

\section{Conclusion}

The application of BIM in construction project management has multiple obvious advantages such as strong visual impact, high bid winning rate, plan accuracy improvement, reduction of unnecessary waste, fast calculation speed and high precision. It contributes to improving construction project management quality. The specific application of BIM technology in construction project management is mainly reflected in engineering design management and engineering construction management. BIM-based construction project management not just has high management efficiency, but also guarantees quality and greatly improves engineering design and construction quality.

\section{References}

[1] Gu Qiuxiang, Study on BIM application in construction project management. Building Materials and Decoration, 2015 (11): 106-107.

[2] Liu Huanhuan, Duan Zongzhi, Peng Zhiwen, Application of BIM technology in refined construction management. Journal of Luoyang Institute of Science and Technology (Natural Science Edition), 2016, 26 (02): 32-37.

[3] Zhu Lianbo, Tian Yunfeng, BIM research literature review in Chinese building industry. Architectural Design Management, 2014 (02): 33-37.

[4] Liu Zhansheng, Zhao Ming, Xu Ruilong, R\&D and application of BIM technology in China. Architecture Technology, 2013 (10) ; 893-897. 